\title{
EL PENSAMIENTO DE RESISTENCIA DE HANNAH ARENDT: UN ANÁLISIS DE LA RELACIÓN ENTRE FILOSOFÍA Y POLÍTICA EN UNA DE LAS LECTURAS DE MIGUEL ABENSOUR
}

\author{
Juan Pablo Yáñez Godoy ${ }^{1}$
}

\section{Resumen/Abstract}

Lasiguienteinvestigación busca dilucidar el sentido tras la consideración que Miguel Abensour realiza sobre Hannah Arendt, concibiéndola como una «figura de resistencia». Exploraremos, por tanto, el significado de este concepto de resistencia en el pensamiento de Abensour, el contexto donde se inscribe, para luego concebir qué contenido adopta en determinada lectura de la obra de Arendt. La lectura estará guiada por la reflexión que Abensour lleva a cabo sobre la obra de la alemana, poniendo énfasis en la manera en que ahí se articula la tensión entre filosofía y política. En ese recorrido, nos detendremos principalmente sobre dos puntos: la operación de «desmontaje» que Arendt lleva a cabo sobre la tradición, el movimiento que esta comporta, y la relación que este ejercicio guarda con la academia, inspirados ciertamente en el combate declarado que Abensour hace de la "empresa académica".

Palabras clave: filosofía, política, academia, resistencia, contra, Hannah Arendt.

\section{THE THOUGHT OF RESISTANCE OF HANNAH ARENDT: AN ANALYSIS OF THE RELATIONSHIP BETWEEN PHILOSOPHY AND POLITICS IN ONE OF MIGUEL ABENSOUR'S READINGS}

This research aims to elucidate Miguel Abensour's consideration about Hannah Arendt as a 'figure of resistance'. Hence the meaning of 'resistance' as presented by Abensour's thought and the context in which it is inserted will be explored, in order to understand the content used by the autor when presenting his reading of Arendt's work. This reading will be guided by Abensour's reflection about the German writer, emphasizing the tension between politics

1 Chileno, Universidad Academia de Humanismo Cristiano. E-mail: jpabloyg@gmail.com 
and philosophy present in her work. Then, two main points will be analyzed: the 'dismantling' operation that Arendt's makes over tradition, the movement that this operation involves, and the relation between the 'dismantling' and the Academy, inspired in the declared attack to the 'academic enterprise' by Abensour.

Keywords: philosophy, politics, Academy, resistance, against, Hannah Arendt.

"Si los filósofos, a pesar de su necesario extrañamiento de la vida cotidiana de los asuntos humanos, han de llegar a una verdadera filosofía politica tendrian que hacer de la pluralidad humana, de la cual surge toda la esfera de los asuntos humanos -en su grandeza y miseria-el objeto de su thaumadzein" (Arendt, 1990: 103$)^{2}$

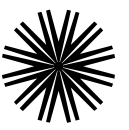

Entre los infinitos rendimientos que puede tener la obra de Hannah Arendt, entre las múltiples oportunidades que su reflexión nutre y alberga, la posibilidad de entrever ahí una filosofía política aparece como una de las más complejas e incluso contradictoria. Ya que, ¿no es Arendt quien deserta de las filas de la filosofía política, de su institución y de su gremio? ¿No podemos acaso comprender su obra como un esfuerzo constante por concebir una política más allá de prejucios filosóficos, de sus intereses particulares sobre la "esfera de los asuntos humanos"? Sin embargo, en este pasaje tan inédito como desconcertante, la entrada para admitir la posible existencia de una "verdadera filosofía política" parece quedar entreabierta.

Pero, ¿qué se inaugura bajo este título? ¿Acaso estamos ante una propuesta de una nueva disciplina? ¿O estamos por el contrario en presencia de una crítica a la filosofía política, a su institución y tradición? ¿Cómo es posible anticipar, esta suerte de desliz arendtiano, esta mención nunca del todo desarrollada sobre

2 "If philosophers, despite their necessary estrangement from the everyday life of human affairs, were ever to arrive at a true political philosophy they would have to make the plurality of man, out of which arises the whole realm of human affairs - in its grandeur and misery-the object of their thaumadzein" (Arendt, 1990: 103). Todas las traducciones, a no ser que se indique lo contrario, son del autor. 
una posibilidad todavía para la filosofía política, que conlleva una cantidad no menor de problemas y que ofrece, desde la obra de Arendt, muy pocas respuestas? Problemas que por cierto se arraigan en el constate rechazo de la alemana por ser considerada "filósofa", pero a su vez de la coherencia de este gesto con la lectura profundamente crítica de la tradición filosófica que, en bastantes sentidos y modulaciones, configura su obra.

Es en este escenario contradictorio, posiblemente aporético, donde Miguel Abensour vislumbra una posible clave de lectura para re-leer la obra de H. Arendt. En efecto, una de las razones por las cuales este autor hacer circular su propia reflexión por esta senda, subyace en lo que podemos considerar como su proyecto filosófico político crítico. Si nos concentramos en la sección itineraria de este proyecto, en los lugares donde se trazan sus coordenadas y objetivos, podemos comprender de manera bastante general esta iniciativa como un intento de concebir la "consistencia de lo político" (Abensour, 2009: 57), su especificidad. "Consistencia" que se piensa, que se dispone, como una pregunta abierta y constante sobre los modos y posibilidades de expresión de la pregunta por lo político, por la manifestación e irrupción de las "cosas políticas" (Abensour, 2009a: 60) en nuestro presente. "Cosas políticas" que, como su críptica ambigüedad lo sugiere, inscriben su sentido en el diagnóstico sobre los lugares de enunciación y los modos en que lo político se concibe y, a ratos, se confina.

Es en este sentido que Abensour centra su atención en el "reciente interés" (Ibíd.: 59) que la filosofía, en su versión institucional y universitaria, demuestra por el problema de lo político. Lejos de todo pesimismo o incluso precariedad en las condiciones de producción que podamos atribuir a la reflexión académica tipificada como "filosofía política", Abensour nota una fecundidad productiva que se expresa en la "creación de revistas, colecciones, organización de coloquios, asociaciones, publicaciones [...]” (Ibíd.), instancias todas que parecen atestiguar la consolidación de una "escena intelectual" (Ibíd.) bastante fértil y en boga. Sobre esta escenario, para este autor el punto radica en ser capaz de distinguir en este nuevo contexto la presencia de "dos gesto intelectuales"(Ibíd.), no tan sólo diferentes, sino que aparentemente contradictorios.

Por una parte, Abensour distingue en este creciente y progresivo interés una tendencia más bien declarada por un regreso hacia la tradición filosófica y a su institución. Movimiento que él entiende como una impulso por la "restauración” (Ibíd.), de su vitalidad, una afirmación de su continuidad y una renovación del interés en sus categorías como modos de 
acceso válidos y útiles para tratar con el creciente interés que lo político, en cuanto fenómeno, despierta. Es este interés el que parece haber abierto una posibilidad para la institución filosófica, en tanto locutor válido que solía ocuparse de estos temas. Se constata un interés y la filosofía, tal como la ciencia política o las ciencias sociales en su actual formulación, responden al llamado. El problema reside en cómo se efectúa esta respuesta, en la manera en que la interpelación de lo político es acogida y correspondida.

En ese contexto, la restauración aparece como la forma que estos intentos describen, demostrando un renovado interés por la filosofía y un regreso a sus categorías. Movimiento que despierta declaradas sospechas a Abensour, y que lo llevan a cuestionar si es que este "retorno de la filosofía política [no tiene] el efecto paradójico de apartarnos de las cosas políticas hasta ocultarlas"(Ibid.: 59). Pero, ¿cómo es posible que el interés por el conjunto de acontecimientos que configura nuestro presente, el acercamiento a esta irrupción de lo político como una de las problemáticas centrales de nuestro tiempo, pueda tener el efecto de apartarnos y de ocultar su mismo sentido?

Una clave de acceso a este asunto puede encontrarse en los autores a los que Abensour desmarca de este gesto "restauracionista", identificándolos con su aparente contrario: con "el retorno hacia las cosas políticas" (Abensour, 2009: 60). Ahí encontramos, entre otros ${ }^{3}$, a Claude Lefort y Hannah Arendt, quienes constituyeron sus reflexiones a partir del reconocimiento expreso de la ruptura de la continuidad de "nuestra tradición de pensamiento político" (Arendt, 1996a: 23) y la afirmación de la inutilidad de sus categorías, en tanto formas de acceder y tratar los acontecimientos brutalmente novedosos de nuestro tiempo. Sucesos que no podemos sino comprender como el advenimiento de los regímenes totalitarios y de la nueva forma de dominación que estos encarna.

Ahora bien, sin ser nuestra intención ahondar en la reflexión sobre el totalitarismo que ambos pensadores presentan, debemos sí considerar que los horrores de la primera mitad de siglo son el episodio concreto que toda

3 En efecto, cuando Abensour habla de esta nueva vía hacia lo político, parece aludir por lo general a dos grandes referentes: Hannah Arendt y Claude Lefort. Ambos pensadores componen para nuestro autor esto que él denomina "paradigma político", diferenciado a su vez del "paradigma crítico" o de la "critica de la dominación", encarnado por los referentes que Abensour rescata de la Escuela de Frankfurt (Horkheimer y sobre todo Adorno). En la articulación de ambos "paradigmas" subyace la posibilidad de instaurar el proyecto filosófico político crítico, siendo cada uno de ellos necesarios en esta tarea. Para mayor referencia sobre la formulación y articulación de estos "paradigmas", es preciso acudir a Abensour, $2009 \mathrm{~b}$. 
reflexión sobre lo político debe tener en cuenta, o al menos establecer como su dato fundacional. Nueva forma de dominación, nueva encarnación del horror y del terror, que rompe, por lo mismo, con toda categoría previa de estos conceptos, demostrando su inoperancia y discontinuidad en tanto herramientas válidas para acceder a su novedad o a su especificidad.

Por ende, dialogar con nuestro tiempo ${ }^{4}$, pensar lo político y su sobrevivencia, después de que "la dominación totalitaria hubiera intentado anular y borrar, para siempre, esta dimensión constitutiva de la condición humana [...]" (Abensour, 2009: 60), implica pensar sobre la fractura de nuestra tradición, sobre la puesta en duda de sus categorías y conceptos como formas adecuadas y pertinentes para comprender nuestro presente. Examen profundo de esta tradición, específicamente sobre su utilidad y su capacidad para mostrar, efectivamente, el objeto de su interés sin subsumir o violentar su radical novedad.

Por lo tanto, la crítica arendtiana de la filosofía, la puesta en cuestión de su misma relación con la política, es para Abensour señal de una reflexión capaz señalar las condiciones de ocultamiento de esta irrupción de lo político. Es señal, en definitiva, de una reflexión que en su crítica tanto de la institución filosófica, de su gremio, como de su tradición, se enmarca dentro de lo que Abensour tan sólo enuncia como "pensamiento de resistencia" (Ibíd.: 62). Pensamiento que, como es posible apreciar, no supone tan sólo un modo de acceso a lo político en tanto dimensión constitutiva de nuestro presente, sino que para albergar dicha posibilidad debe lidiar, ya veremos de qué manera, con el ocultamiento que los intentos restauracionistas llevan a cabo. En efecto, Abensour lleva un paso más allá su análisis sobre el panorama actual, configurando las posibilidades del "regreso a lo político", a sus preguntas o sentidos, como una ejercicio de resistencia sobre los influjos, no tan sólo de este movimiento de restauración, sino de su forma y lugar institucional: la "empresa académica" (Ibíd.).

En lo que sigue intentaremos concebir en qué consiste esta forma de pensamiento, cuál es su relación con la crítica que $\mathrm{H}$. Arendt realiza de la filosofía y qué nos dice este análisis acerca de la posición que la alemana ocupa, luego de su pública salida del gremio de los filósofos y su fundamental crítica a la tradición filosófica. Intentaremos averiguar qué posibles resonancias tiene esta crítica a la "empresa académica" que tan sólo

4 De manera más completa Arendt nos señala: "Si queremos estar en casa en esta tierra, incluso al precio de sentirnos en casa en este siglo, hemos de tomar parte en el interminable diálogo con la esencia del totalitarismo" (Arendt, 2005 : 393). 
nos señala Abensour, pero ya en un contexto arendtiano. Exploraremos, por lo tanto, en qué consiste el contra que configura la lectura de este filósofo francés sobre la obra de la alemana, desplegando ciertamente algunas de las posibilidades que subyacen en esta perspectiva.

\section{Arendt, figura de resistencia}

Como anticipábamos anteriormente, el retorno de las "cosas políticas" supone no tan sólo una denuncia de esta "empresa académica" - una reacción ante el olvido que su registro superpone a la irrupción de las "cosas políticas-, sino que encierra en ese mismo movimiento una suerte de propuesta en tanto "pensamiento de resistencia". No obstante, el sentido de este "registro otro" no adquiere una densidad apropiada hasta que nos aproximamos a uno de sus ejemplos más concretos: la lectura que hace Abensour de $\mathrm{H}$. Arendt. Concreto, pero no en tanto encontraremos en Arendt las condiciones o la forma en que este tipo de pensamiento se estructura, sino en tanto la alemana es primordialmente para Abensour una "figura de resistencia" (Abensour, 2009c: 233), es decir, un ejemplo encarnado del compromiso con el retorno y el "redescubrimiento" [redécouverte] de lo político (Abensour, 2009: 62).

Arendt, en este sentido, presenta una reflexión que ha sabido escapar y denunciar lo que Abensour denomina gesto restaurador, dando forma a una particular operación con la tradición filosófica y con el gremio mismo de los filósofos. Expresión así de un "contra" que Abensour comprende a través de la "figura de la resistencia", pero en un sentido más exacto, en la expresión de determinada forma de "desconocimiento" [méconnaissance]", cierto desaire o desprecio. Nuestro autor parece leer la posición que Arendt adopta frente a la filosofía política bajo esta actitud, o como él mismo nos indica, bajo:

5 “[M]éconnaissance sous forme d'une résistance". (Abensour, 2009 : 236), nos dice Abensour, utilizando esta conflictiva palabra [méconnaissance], porque si bien podemos entender esta actividad como un "desprecio", como nos indica la traducción al español (Abensour, 2007: 99), tenemos que entender la complejidad del ejercicio que Arendt efectúa. No está simplemente "despreciando" a la filosofía, del mismo modo que no está "subestimando" su valor, sino que está trabajando sobre ella, generando en este movimiento su resistencia. No hay una épochè total o una suspensión absoluta, sino que está más bien operando en constante atención de su tradición y, al mismo tiempo, sobre una tensión que la lleva, de cierto modo, más allá de sí misma. Elegimos, por esta razón, la forma de un "desconocimiento", porque logra de un modo más apropiado nombrar estos dos movimientos, la animadversión o desconfianza hacia la filosofía, pero el despliegue de un ejercicio sobre y a ratos en sus límites. 
“[...] un desconocimiento en forma de resistencia; como si se confesara: ciertamente, Hannah Arendt critica la filosofía política, 'sí, pero a pesar de todo', permanece como filósofa de la política, haciendo obra de filosofía política" (Abensour, 2009c: 236).

En este sentido, ¿cómo entender la profundidad de la reflexión arendtiana, cuyo despliegue se efectúa sobre la filosofía, sobre lo que ella denomina "nuestra tradición de pensamiento político" y a través de este conjunto de filósofos que la componen, bajo la forma de un "desconocimiento", de un "desprecio"? ¿No pasa su análisis y concepción de lo político por un ejercicio con la tradición filosófica? ¿No es Arendt una pensadora de la filosofía? Es éste el problema que Abensour parece atestiguar en este fragmento, dejando entrever la complejidad de juzgar y dirimir la posición de Arendt de un lado, como "teórica política", o del otro, como "filósofa política."

Así, si concebimos este problema desde determinada perspectiva arendtiana, podemos describir la tarea de la alemana como un ejercicio interpretativo crítico "cuya meta es descubrir los orígenes verdaderos de los conceptos tradicionales, para destilar de ellos otra vez su espíritu original" (Arendt, 1996b: 21), "desmontando" [dismantle $]^{7}$ su lugar en la tradición filosófica en la que se circunscriben, para considerarlos a la luz de la propia experiencia que les dio forma. Es en este ejercicio de "desmontaje" donde nos vemos inclinados a inscribir esta especie de "desconocimiento", adquiriendo éste ya no el modo de la ignorancia o del desprecio, sino de un ejercicio más bien complejo, donde la filosofía, la tradición filosófica en este caso, es fuente y objeto de análisis. Es en este sentido que Abensour nos señala:

“'Una suerte de fenomenóloga', H. Arendt invoca la fenomenología contra la filosofía apelando a una suerte de epokhé, que en este caso, no persigue la liberación del psicologismo o de la sociología, sino de la filosofía misma. Sólo la puesta entre paréntesis [mise entre parenthèses] de la filosofóa política permitiría el acceso a las cosas políticas mismas, su consideración con una 'mirada no velada por la filosofía.'” (Abensour, 2009c : 236)

6 Es la misma Arendt la que se encarga de hacer esta diferencia, cuando interpelada por Günter Gaus responde: "Yo no pertenezco al círculo de los filósofos. Mi profesión, si puede hablarse de algo así, es la teoría política. No me siento en modo alguno una filósofa. Ni creo haber sido admitida en el círculo de los filósofos [...]" (Arendt, 2005: 17).

7 "Claramente me he unido en las filas de aquellos que hace ya un tiempo han intentado desmontar la metafísica, y la filosofía con todas sus categorías, tal como la hemos conocido desde los comienzos en Grecia hasta hoy en día" (Arendt, 1977: 212). 
"Puesta entre paréntesis" que no nos sugiere tanto un distanciamiento, sino más bien un acercamiento profundo a esta tradición, pero ya no con el ánimo de perpetuar su permanencia o continuidad, sino todo lo contrario, para efectuar una búsqueda ahí de los puntos donde esta continuidad es puesta en jaque. De este modo, esta suspensión se aplica a los influjos de lo que hemos considerado anteriormente como gesto restaurador, a su pretensión institucional de continuidad, con vistas a acceder a estos lugares que permanecen ocultos a su reflexión y ajenos de su preocupación.

Lugares que atestiguan las grietas de esta tradición, sus sesgos, pero que representan el suelo donde se sostiene su relación con lo político. En ese sentido, la visibilización de estos puntos guarda consigo la posibilidad de suspender la tradicional significación de los elementos y conceptos comprendidos bajo la categoría de "políticos" y con ello relegados a la rama de la filosofía encargada de su trato. Suspensión que podemos entender ya no como un simple dejar de lado, sino como una liberación de su significado tradicional, que a partir de un sesgo constitutivo, intenta domesticar y amoldar su significado a partir del interés de un grupo particular. Manipulación que está detrás de la constitución de la manera tradicional de pensar lo político y que responde a una relación específica con estos momentos incómodos de su constitución.

Estos lugares son concebidos por Abensour como "los puntos ciegos de la tradición” (Ibíd.: 244), sus momentos "impensados" (Ibíd.: 238), lugares que si somos exactos no son desconocidos por esta tradición, sino que son más bien negados, objetos de un ocultamiento o una relación velada con su existencia y posibilidades. Lugares que se inscriben en la conflictiva relación que guarda la actividad filosófica con la dimensión política, en el tránsito problemático de una esfera hacia la otra. Conflicto que nuestra tradición de pensamiento político ha desconocido, haciendo de la filosofía política misma una disciplina que se constituye, quizás intencionalmente como a continuación intentaremos concebir, sobre el desconocimiento del conflicto que se encuadra entre filosofía y política. Conflicto que para Arendt no sólo representa un foco de problemas para ambas dimensiones, sino que se inscribe en el episodio fundamental de nuestra tradición tanto filosófica como política, haciendo de esta ceguera su condición estructural.

En ese sentido, la relación entre filosofía y política se calibra en Arendt bajo la forma de una "tensión", una hostilidad primigenia entre ambos conceptos, entendiendo bajo cada uno de ellos el ejercicio de una actividad particular, que inaugura a su vez una dimensión aparentemente 
contradictoria, disímil y en conflicto con la otra. "Cuando yo hablo de estos temas [ nos señala Arendt] siempre menciono que hay una tensión entre filosofía y política. Es decir, entre el hombre como ser que filosofa y el hombre como ser que actúa" (Arendt, 2005: 18). Como es posible apreciar, Arendt transforma la relación entre filosofía y política en una distinción, como pertinentemente nos aclara Abensour, "entre dos formas de experiencia” (Abensour, 2009c: 244). Experiencias que, como nos señala la alemana, adoptan el modo de dos actividades que entran en tensión a partir de la aparente incompatibilidad entre su ejercicio. En este sentido, el conflicto es reconducido desde la definición nominal de ambas esferas a la dimensión que dicha definición pretende nombrar, compuesta por la actividad que le entrega su vitalidad o movimiento.

En esa línea, si concebimos que esta relación conflictiva se inscribe en el episodio fundacional tanto de nuestra tradición de pensamiento político como de la misma disciplina filosófica, podemos comprender el esfuerzo aredntiano por "descubrir los orígenes verdaderos de los conceptos tradicionales", como un intento de entrever este vínculo vedado o intencionalmente oculto. Paso que por cierto determina, como uno de los objetivos del pensamiento de Arendt, la búsqueda de los episodios fundacionales donde se hace posible concebir la expresión aún no silenciada de esta relación polémica y fundante. Episodios que no sólo logran iluminar la experiencia originaria de los conceptos que conformar nuestra tradición, sino que de paso pone en jaque su continuidad y su propiedad al momento de proclamarse a sí misma como la encargada de analizar, tematizar y determinar los problemas, formas y contenido de lo político.

Es en este sentido que Arendt, a partir de su contra la filosofía politica, se vuelve una figura ejemplar de lo que nuestro autor concibe como "el retorno a las cosas políticas", abriendo nuevas posibilidades para el pensamiento de lo político a partir de su búsqueda de los sentidos olvidados y ocultos de los conceptos tradicionales. Búsqueda que no sólo logra escapar a la influencia del gesto restaurador a partir de su renuncia al título de filosofía política, sino que, al cuestionar de modo radical la relación misma que entablan estos términos, pone en duda la vialidad de dicha disciplina. Examen crítico de la tradición que vuelve compleja la relación de Arendt con respecto a la filosofía y que hace de su posición, para nuestro autor, un asunto problemático. En efecto, nos seńala: 
"Si ella está determinada a distinguir, de la manera más clara posible, entre dos formas de experiencia -la política y la filosófica- epodemos concluir que va a prescindir, definitivamente, de la filosofía para acercarse a la política?” (Abensour, 2009c: 244).

Sobre todo lo dicho, volvamos pues a a la pregunta que enunciábamos ya desde el inicio: ¿podemos concebir a la reflexión arendtiana como una búsqueda que opera a espaldas de la tradición y de la disciplina filosófica? $\mathrm{El}$ problema parece permanecer. Con el propósito de intentar comprender este asunto en su profundidad, debemos vislumbrar el modo en que esta operación de "desmontaje" ocurre, la forma en que esta búsqueda de los episodios y experiencia original tiene lugar en Arendt y el modo cómo se estructura. Búsqueda que no sólo nos aproximará a la forma en que su reflexión adopta esta misión, sino que guarda la posibilidad de entregarnos un contenido más concreto de la "consistencia" que posee este retorno a las "cosas políticas" del que Abensour tanto nos habla, mostrando la especificidad de su dimensión bajo un nuevo prisma.

\section{Politica, libertad y polis}

Si nos adentramos un poco más en su obra, Arendt comprende que tras filosofía y política existen dos "modos existenciales" ${ }^{8}$ contrapuestos, con su propia historia, y que adquieren expresión mediante el ejercicio de sus actividades particulares. Modos que se constituyen a partir de diferentes experiencias, una arraigada en la experiencia del pensamiento o de la «vita contemplativa», la otra en la experiencia de la libertad, la acción y los «asuntos humanos» o de la «vita activa». Distinción tan clásica como central en la obra arendtiana y que Abensour recoge, en tanto lugar donde reside gran parte de la envestida de la alemana contra la tradición, en este caso, específicamente filosófica.

Privilegiando el carácter polémico de Arendt (aspecto que no es muy difícil de encontrar), Abensour lee la hostil relación entre "vita contemplativa" y "activa" como la tensión fundante de la relación estructural de la filosofía hacia la política y, por ende, estructural más que de la filosofía política, de

8 Esta expresión aparece en múltiples contextos, pero en el siguiente se evidencia de mejor manera la contraposición entre una dimensión filosófica y la "calle" en tanto dimensión política: "La verdad filosófica, cuando entra en la calle, cambia su naturaleza y se convierte en opinión, porque se ha producido [...] no sólo un paso de un tipo de razonamiento a otro sino de un modo de existencia a otro" (Arendt, 1996d.: 250). 
lo que nuestro autor denomina como la "política de la filósofos" (Abensour, 2009: 262). Matiz que Abensour introduce, quizás, en busca de preservar cierta esperanza para una posibilidad aún de filosofía política. No obstante, ¿qué compone esta política de los filósofos? ¿No nos indica la diferencia arendtiana que la política es una dimensión de otro orden que la filosofía? ¿No serían así los filósofos apolíticos?

En vista a entregar alguna respuesta a estas preguntas debemos entrever al menos qué estamos comprendiendo aquí por política, sobre qué suelo se estructura esta noción y qué papel juega ahí la filosofía. Para ello, debemos retrotraer nuestra atención, con cierta necesidad, al escenario que la polis ofrece. Es este lugar, para Arendt, el que "ha determinado decisivamente [...] la concepción europea de lo que es verdaderamente la política y su sentido" (Arendt, 200: 68), ya que es aquí donde tiene lugar una experiencia de libertad que, aunque de modo muy tenue, todavía resuena tras los conceptos y categorías con las que entendemos la política hoy en día.?

Esa importancia hace que Arendt vuelva, de manera constante, a este lugar fundacional, intentando concebir un escenario donde política y libertad mantienen todavía un relación de identidad. Política y libertad, a la vez; no una antes que la otra, como su condición de posibilidad, su antecedente o a su pesar. Arendt está enfrentando así el "prejuicio moderno de que la política es una necesidad ineludible y que la ha sido siempre y por doquier" (Ibíd.: 71). Prejuicio que determina a la política como un antecedente para el ejercicio de la libertad, como un rodeo necesario, tortuoso y molesto, abocado a resolver los problemas que derivan de nuestra convivencia y que atentan con su puesta en práctica. Lejos de esta noción, Arendt encuentra en la polis una experiencia de la libertad diferente, que ya no mantiene una relación diacrónica con el ejercicio de la política, donde una sería una suerte de condición de posibilidad para la otra, sino donde ambos conceptos se piensan en sincronía. Experiencia que, a pesar de su disconformidad con la concepción moderna de la política, serviría de referente para nuestra tradición de pensamiento.

9 Debemos aclarar que aquí no estamos, por cierto, atendiendo a toda problemática que pueda existir tras la diferenciación entre la política y lo político (para ello véase Mouffe, 2007), sino que nos estamos ciñendo a las traducciones clásicas de estos conceptos (politics para Arendt y politique) al español. Así, en el caso de Arendt se ha privilegiado el uso de "la política" y para Abensour el de "lo político", aunque como es posible notar, esta diferencia responde más a una discrepancia de las traducciones que ha un problema de otro orden. 
Concebido en estos términos, el "contra" de Arendt aparece en este contexto como un contra la concepción moderna de lo político, como una disputa sobre el contenido y modos en que su relación con la libertad se ha dispuesto. No obstante, ¿¿de qué forma comprende Arendt a esta libertad? ¿En qué medida la polis da pistas para comprender esta relación sincrónica entre la puesta en acto de la política y el ejercicio de la libertad? Preguntas que nos obligan no sólo a dar unos cuantos pasos más dentro de la reflexión arendtiana, sino a elegir un sendero que logre encaminar esta ruta. En este punto, podemos optar por concebir esta relación entre política y libertad a partir de uno de los textos de Arendt predilectos de Abensour que, a pesar de que no fue escrito para ser publicado ${ }^{10}$, siendo más bien un proyecto o una estructura de un truncado libro, nos presenta un acceso idóneo hacia esta problemática.

Nos referimos, por cierto, a ¿Qué es la política?, donde el "contenido auténtico y el sentido de lo político mismo", es concebido bajo el nombre de "libertad de movimiento" (Ibíd.: 79). Así, si estamos intentando tender una relación de identidad entre libertad y política, la libertad de movimiento sería, en su expresión, la constatación efectiva de que la política está ocurriendo y de que la libertad está teniendo lugar. Pero, ¿a qué se refiere Arendt con ello?

A pesar de ser una mención más bien breve ${ }^{11}$, Arendt configura esta "libertad de movimiento" a partir de dos acepciones similares pero no idénticas. Acepciones que apelan a elementos fundamentales dentro de su concepción de la política. Por una parte, Arendt la define como "la [posibilidad] de ejercer la libertad y comenzar algo nuevo e inaudito" (Ibíd., p. 79). Por otra, como "la libertad de hablar con muchos y así darse cuenta de que el mundo es la totalidad de estos muchos" (Ibíd). Especificaciones de esta acepción de la libertad que remiten, por cierto, a la acción y el discurso,

10 Was ist Politik? corresponde más bien a apuntes de un proyecto de publicación frustrado, material que comenzó su gestación en 1956 y que finalizó con la denegación de la Fundación Rockefeller a financiar su concreción, ya en 1959. Carta a dicha fundación que está, por cierto, incluida junto con los esbozos de las diferentes modulaciones que tuvo el proyecto en la recopilación de Ursula Ludz en 1993.

11 En efecto, la libertad de movimiento, en tanto concepto, tiene una mención y trato bastante acotado. El motivo por el cual destacamos aquí su importancia es más bien metodológico, en tanto Arendt reúne en su definición las acepciones más cruciales que su reflexión concibe de la libertad: como libertad de actuar y libertad de hablar. En este sentido, estamos haciendo uso de este concepto para introducir el problema que Arendt cifra tras la relación entre libertad y política, esto en consideración de que es por estos senderos por donde transita su formulación del contra la filosofía política. 
al actuar y el hablar, o en su versión griega y más memorable, a "los grandes hechos y las grandes palabras" (Arendt, 1996c: 53).

Memorable por cierto, ya que la grandeza que aquí Arendt quiere destacar nos remite a la profunda importancia que "hechos y palabras" para ella guardan y a la forma en que estas actividades se diferencian tanto de la labor como del trabajo. Es este esfuerzo, el de diferenciar labor, trabajo y acción el que la alemana emprende en una de sus obra capitales, The buman condition (Arendt, 1998), intentando dar con la especificidad de cada una, haciendo de la política el polo donde estas actividades gravitan y demostrando el grado de relación que éstas guardan con la particular expresión del "vivir juntos" al que que ella está intentando acceder. Como podemos anticipar, es en la acción donde esta búsqueda recala, ubicando en el espacio y tiempo que ofrece la polis el lugar idóneo para adentrarse en la especificidad de la dimensión política.

En efecto, Arendt ve en la polis más que un asentamiento físico con una ubicación geográfica e histórica determinada. La alemana va más allá de las ruinas, más allá de la "ciudad-estado en su situación física" (Arendt, 2000: 221), para comprender por "polis" "la organización de la gente tal como surge de actuar y hablar juntos [...]" (Ibíd), denotando la radical importancia de "hechos y palabras", actividades que no sólo ocurren en este espacio, sino que lo constituyen como tal.

Si nos adentramos con mayor propiedad en la dimensión que la acción nos ofrece, podemos comprender cómo la afinidad entre la fundación de la polis y "hechos y palabras" está determinada por el arraigo que estos conceptos tienen en lo que Arendt entiende por pluralidad. Si cada una de las actividades de la vita activa tiene una "condición"12, es decir situaciones o circunstancias que hacen posible su desenvolvimiento, y si la condición de la labor es la "vida misma" (Arendt, 2000: 21), en tanto es mediante esta actividad que nos ocupamos de nuestras necesidades biológicas, de sobrevivir o de mantenernos vivos; y si las condición del trabajo es la "mundanidad" (Ibíd), en la medida en que el trabajo se aboca a la construcción de objetos, cosas y artificios con los que habitamos el mundo, con los que nos asentamos en él y que nos permiten el arraigo propiamente humano que con él guardamos; la acción posee como condición la pluralidad, el "hecho

$12 \mathrm{Al}$ respecto Arendt nos aclara "Para evitar el malentendido: la condición humana [así como cada una de las condiciones atadas a cada una de sus actividades] no es lo mismo que la naturaleza humana, y la suma total de actividades y capacidades que corresponden a la condición humana no constituye nada semejante a la naturaleza humana" (Arendt, 2000: 23,24). 
de que los hombres, no el Hombre, vivan en la Tierra y habiten el mundo" (Ibíd.: 22).

La pluralidad arendtiana no está mentando así una "forma" del "vivir juntos»" o el modo en que este se organiza o se efectúa, sino que nombra una suerte de pre-requisito para acceder a su carácter específico, para pensar su "consistencia", nos diría Abensour, sin violentar o subsumir su carácter.

En este contexto, acción y discurso, al ser actividades condicionadas por la pluralidad, corroboran la existencia de esta condición cada vez que son ejercidas. A diferencia de labor y trabajo ${ }^{13}$, "hechos y palabras" nos arrojan a esta pluralidad, poniéndonos en una relación directa con los demás, con los otros. Por su parte, actuar implica comenzar algo nuevo, dar inicio a un nuevo proceso, cualidad que se arraiga en otra condición: la "humana condición de la natalidad" (Arendt, 2000: 201). En efecto, la acción expresa ese inicio que todos somos, que entra al mundo junto con nuestro nacimiento y "al que correspondemos comenzando algo nuevo [...]"(Ibíd.), nos dirá Arendt, leyendo tras esta actividad la posibilidad profundamente humana de iniciar nuevos procesos y de interrumpir los que ya existen.

Inicios que no están determinados por nuestra necesidad de sobrevivencia, que no se inscriben en el cíclico movimiento que describe nuestra vida biológica, que no tienen como fin la utilidad de los instrumentos o las cosas que fabricamos producto del trabajo, sino que tienen como norte los intereses que se tienden a través de las relaciones que entablamos con los otros. Relaciones que se producen cada vez que hombres y mujeres conviven juntos, cada vez que habitan un espacio lo suficientemente ameno para que éstos pueden mostrarse ante los demás. Aparición o revelación que es uno de los efectos más importantes que Arendt lee en acción y discurso, su "unique distinctness" (Arendt, 1998: 176), su cualidad de "vivir como ser distintos y único entre iguales" (Arendt, 2000: 202) y de poder expresar dicha distintividad.

Así y si volvemos a nuestra pregunta por la "libertad de movimiento", podemos vislumbrar de manera más apropiada cómo esta acepción reúne tanto los atributos que contiene la acción, esta posibilidad para "comenzar

13 En efecto, "La actividad de la labor no requiere de la presencia de otro, aunque un ser laborando en completa soledad no sería humano [...]. El hombre que trabaja, fabricara y construyera un mundo habitado únicamente por él seguiría siendo un fabricador [...]. Sólo la acción es prerrogativa exclusiva del hombre; [...] y sólo ésta depende por entero de la constante presencia de los demás" (Ibíd.: 37, 38). 
algo nuevo e inaudito", como los efectos y consecuencias del discurso, en tanto "libertad de hablar con [los] muchos" (Arendt, 2009: 79). En este sentido, el énfasis que Arendt pone en el movimiento puede interpretarse en razón de la publicidad que el ejercicio de esta libertad requiere. Al constituirse a partir de acción y discurso, y al representar cada una de estas actividades una expresión de la pluralidad humana, de la "contigüidad"14 y presencia de los otros, la libertad de movimiento supone nuestro ingreso en la esfera donde este acto presencial es llevado a cabo. Esta dimensión es, por cierto, la "esfera pública" 15 , lugar en el que nos insertamos por medio de la acción, mostrándonos ante sus integrantes, y donde podemos expresar nuestra opinión ${ }^{16}$, nuestro parecer, acerca de lo que ahí aparece.

De este modo, el movimiento que esta forma específica de libertad nombra, apunta precisamente al tránsito que debe efectuar el que pretende actuar o emitir una opinión, desde la soledad de su privacidad hacia la esfera pública. Tránsito que Arendt comprende como el paso desde una esfera hacia otra, desde un "modo de existencia" a otro, movimiento que nos lleva a abandonar la esfera privada, constituida por las actividades que no requieren de la presencia de los demás -como ocurre con la labor, el trabajo y, por cierto, con el pensamiento-, para dirigirnos a "los muchos" y al espacio donde estos aparecen y donde nosotros podemos, tal como ellos, mostrarnos ante su atención. Es este el atributo de la "esfera pública", una suerte de caja de resonancia que magnifica no sólo nuestra aparición en esta escena, al ofrecer una tribuna de mayor escala a la "revelación" que estos actos distintivos efectúan, sino que además multiplica las posibilidades de que los demás interfieran, participen o continúen el nuevo proceso que, en este caso, la acción ahí comienza. Lo mismo ocurre con el discurso, el cual tiene en la esfera pública una propagación difícilmente calculable, dada nuestra abierta incapacidad de restringir o manejar el tránsito de una idea, una opinión, un mensaje o una historia una vez que su contenido se hace público.

14 Concepto que Arendt utiliza en el siguiente sentido: la "cualidad reveladora del discurso y de la acción pasa a primer plano cuando las personas están con otras, ni a favor ni en contra, es decir, en pura contigüidad humana" (Arendt, 2000: 204).

15 "[L]a acción necesita para su plena aparición la brillantez de la gloria, sólo posible en la esfera pública” (Ibíd.).

16 La opinión, para Arendt, no sólo expresa un derecho constitucional que debe ser asegurado en orden de preservar las libertades personales de cada individuo, sino que, bajo su modulación griega, esencialmente se define como la posibilidad humana de intercambiar "puntos de vista", la cual supone determinada acepción del "comprender", de "mirar el mundo desde la posición del otro, al ver lo mismo bajo aspectos muy distintos y, a menudo, opuestos" (Arendt, 1996c: 60). 
Amplio e intrincado universo conceptual que determina las coordenadas donde se ubica la concepción política de Hannah Arendt y donde su posición frente a la filosofía política adquiere su sentido. Pensar la "libertad de movimiento", sin este paso previo, nos puede llevar, por ejemplo, a intentar concebir su existencia a partir de nuestro prisma moderno, pensando su contenido en razón del "derecho al desplazamiento", incluso de la "libertad personal" o del compromiso estatal por su "seguridad". Cuando el desplazamiento que aquí se intenta mostrar, no parece coincidir con el tránsito de un lugar a otro -que en su formulación moderna en realidad coincide de manera general y especialmente en nuestro contexto local con el desplazamiento de la privacidad del hogar al espacio de trabajo productivo-, sino más bien con el tránsito de un "modo de existencia" a otro, de la privacidad de la esfera privada, del $o \hat{\imath} k o s^{17}$, a la escena pública en tanto "espacio de libertad" (Abensour, 2009c: 241). Así, si quisiéramos encontrar un correlato aproximado de ese movimiento en nuestros días, tendríamos que buscar precisamente en los lugares donde tal publicidad se efectúa, donde los muchos todavía se reúnen en pos de sus intereses comunes, a favor de una causa o interés común, intentando insertar un nuevo comienzo o interrumpir algún viejo proceso. Proceso que, tal como Arendt nos enseña y como Abensour lo remarca, está cargado de heroísmo y de valentía ${ }^{18}$. Conceptos importantes para Abensour y sobre los que volveremos cerca del final de nuestro recorrido.

Mientras tanto debemos preguntarnos ¿qué rol juega en este contexto griego la filosofía? O de manera más precisa, ¿cómo se articula en esta escena la filosofía?

\section{La politica de los filósofos: la Academia}

Uno de los principios que a Abensour le resultan más atractivos de la reflexión arendtiana, una de las consignas sobre las que se concentra su atención con mayor fuerza, es la exigencia que la alemana se autoimpone

17 Es el mismo Abensour quien nos entrega una definición de ese espacio, del ồkos (del griego "casa"), como el "hogar o [...] la familia", entendiendo por ello un "espacio de necesidad orientado hacia la reproducción de la vida bajo la autoridad despótica del jefe de familia" (Abensour, 2009c: 241).

18 En efecto, nos señala Arendt: "La valentía es la primera de todas la virtudes políticas y todavía hoy forma parte de las pocas virtudes cardinales de la política, ya que únicamente podemos acceder al mundo público común a todos nosotros, que es el espacio propiamente político, si nos alejamos de nuestra experiencia privada y de la pertenencia a la familia a la que nuestra vida está unida" (Arendt, 2009: 73, 74). 
por "abordar la política "con ojos no velados por la filosofía” (Abensour, 2009c: 256). Hemos, de cierta forma, experimentado un fragmento de ese ejercicio, a través de nuestra lectura de la polis y la centralidad que ahí juega la concepción arendtiana de acción y discurso. Ese trabajo, ese rescate y resignificación de una vida política previa a la interpretación filosófica, responde precisamente a este esfuerzo por ir más allá del "velo de la tradición", intentando acceder a una configuración específica del "vivir juntos" fundada en la identificación de la política con la libertad. No obstante, la característica específica que diferencia esta acepción de lo político de la que nos entrega la filosofía política, en esta formulación primigenia, no ha sido aún enunciada.

Abensour define esta reflexión de lo político des-velada, más allá de los sesgos filosóficos, como un "regreso a la acción misma” (Ibíd.), ejercicio del que sí algo hemos señalado. No obstante, el modo por el cual este acceso se construye supone tres condiciones.

La primera de ellas parece estar ya en esta consigna que Abensour lee en Arendt, puesto que nos exige "no considerar la política desde el punto de vista de la filosofía, del interés de [un] grupo de los filósofos”(Ibíd.). La segunda es más específica, definiendo ese "no considerar" en razón de un "no someter la actuación política a la distinción y a la jerarquía entre dos modos de existencia [...]" (Ibíd.), aludiendo, por cierto, a la necesaria distinción entre la actividades de la "vita activa» y "vita contemplativa», especificando que el problema radica en la re-jerarquización de la política que esta última realiza sobre la constitución de la primera. Transgresión que consistiría en una re-valorización de la escena pública y sus elementos constituyentes la acción, el discurso, la pluralidad y todos los demás conceptos que aquí hemos mencionado-, en razón de las condiciones que posibilitan el libre ejercicio de la filosofía y el pensamiento. La tercera de estas condiciones puede ser concebida a la luz de la dos anteriores, al exigirnos "no reproducir los nudos de la tradición [...]" (Ibíd.), entendiendo por éstos los efectos y consecuencias específicas de la re-significación de la política a partir o en pro del ejercicio de la contemplación. Consecuencias que estriban en "el miedo a la acción" (Ibíd.) o la fijación filosófica con la mortalidad y los efectos de esta actitud en la revalorización de la política.

Si bien esta última exigencia hace hincapié en uno de los prejuicios que configura el acercamiento filosófico a la política, que son en mayor o menor grado fundantes y estructurales a toda filosofía política tradicional, cada uno de ellos se funda a su vez en la transgresión filosófica de la vida 
política, o si somos más específicos, en la revaloración de la política que surge luego de que los filósofos efectúan esta suerte de retirada de la polis. En otras palabras, más que el surgimiento del ejercicio de una actividad por completo diferente de la política - del pensamiento entendiendo por éste una sustracción de la caótica vida pública para refugiarse en el solitario "territorio de los invisibles"19-, podemos inferir que es el retiro y la posterior institucionalización de ese exilio, bajo la forma de la Academia, el gesto que determina la relación gremial de los filósofos con la polis.

Destacamos aquí esta suerte de segundo momento en la relación de la filosofía con la política, ya que si consideramos a la filosofía sin una institución que la cobije, sin un lugar que proteja las condiciones que la posibilitan, estamos en realidad concibiendo a los filósofos todavía como parte de la polis. Como personajes díscolos o extravagantes tal vez, en tanto su característica específica reside en el ejercicio del pensamiento, actividad que supone precisamente abstenerse de toda acción. Abstención que, bajo la configuración de la polis como un espacio de aparición, implica una suerte de desaparición, una negativa a aparecer ante los demás por medio de actos. Principio por lo demás fundacional de esta ciudad-estado. Pensamiento que ocurre en soledad, preferentemente cuando nadie nos molesta, ni siquiera nuestro cuerpo ${ }^{20}$, y como una actividad que no aparece ante nadie más que aquel que la ejecuta.

No obstante, la posición solitaria de aquellos que ejercen el pensamiento es, sin la academia, todavía una postura personal. Por lo mismo, su impacto en la escena pública se efectúa desde una posición individual, a los ojos de los demás no muy distinta de la opinión y abierta, por cierto, al juicio colectivo. Posición que está más cercana al ridículo público ${ }^{21}$ que a una

19 "Es como si al pensar uno se retirase a un lugar imaginario, al territorio de los invisibles, del que no sabría nada si careciese de la facultad de recordar e imaginar. El pensamiento anula las distancias temporales y las espaciales. Permite anticipar el futuro, reflexionar sobre él como si ya estuviera presente y recordar el pasado como su aún no hubiera desaparecido" (Arendt 2002: 107,108). Por lástima, en esta ocasión nuestro recorrido no nos permitirá detenernos como quisiéramos a examinar la importancia del análisis que Arendt hace del pensamiento y de su importancia para comprender la relación entre filosofía y política. Examen que aquí sólo acogemos en su relación con la formación de la Academia, pero que posee implicaciones directas sobre las condiciones de posibilidad que nos permiten admitir una verdadera filosofía política. Para mayor referencia sobre este punto, véase Abensour 2006: 151-226.

20 "El pensamiento es rápido porque es inmaterial, y esto, a su vez, ayuda a explicar la antipatía de muchos de los grandes metafísicos hacia sus propios cuerpos. Para el yo pensante, el cuerpo no es nada más que un obstáculo" (Arendt, 2002: 69).

21 En efecto, Arendt reconoce que "[l]a hilaridad antes que la hostilidad es la reacción natural de la mayoría ante la preocupación del filósofo y la aparente inutilidad de sus asuntos" (Ibíd.: 104). 
transgresión significativa de los conceptos fundacionales de dicho espacio. De modo que, en ese contexto pre-académico, el filósofo sigue inserto en esta "esfera de los asuntos humanos", en sus condiciones y avatares.

De esta manera, la modulación de la libertad como la capacidad humana de "compartir palabras y actos", de fundar la política, y de paso la polis, en razón de la libertad, no se ve radicalmente re-significada hasta que la Academia se establece como un espacio diferenciado del espacio de aparición pública. En este sentido, lo significativo del paso desde el Ágora a la Academia estriba en el cambio de posición que el filósofo adopta en relación a los demás integrantes de la polis. O dicho de otro modo, la transgresión del concepto de la libertad que la polis encarna alcanza un contenido político cuando el filósofo, más que poner en duda la función y sentido de esta forma de comunidad, vuelve su atención hacia la política. Retorno que está motivado ya no por una premisa filosófica, sino más bien por las condiciones que posibilitan dicho ejercicio.

En efecto, cuando Platón describe el camino "ascendente" que debe emprender aquel que quiera contemplar la idea del "verdadero Bien", junto con las ideas de justicia, belleza o bondad, debe recurrir en un principio a las nociones de "responsabilidad" o "compasión" para explicar por qué es necesario el regreso de este personaje a la escena pública y a la preocupación por los "asuntos humanos" 22 . Regreso no exento de problemas y peligros, pero que es por cierto necesario en la formación del "filósofo rey", personaje que encarna este conflicto. Finalmente, es el mismo Platón quien asume que la "compasión" no es justificación suficiente para motivar este regreso, aludiendo a determinada necesidad de equidad en su confección del Estado ideal ${ }^{23}$, el cual debe no sólo resguardar, sino también ofrecer la oportunidad de emprender el ejercicio contemplativo, filosófico y dialéctico. En ese sentido, la filosofía y su actividad son la muestra palpable de que el estado

22 Es precisamente la "compasión" el motivo por el cual el ex-prisionero de la caverna de Platón vuelve para intentar liberar a sus compañeros. "Si recordara entonces su antigua morada y el saber que allí se tiene, y pensara en sus compañeros de esclavitud, ¿no crees que se consideraría dichoso con el cambio y se compadecería de ellos?” (Platón, 1988: 341).

23 Constatando la abismal diferencia entre la felicidad de la contemplación y la "miserable vida" de aquellos que se ocupan de los asuntos públicos, Platón se ve forzado a un principio de contractualidad entre aquel formado por la ciudad para gobernar, el filósofo, y el desempeño de su cargo, señalando: "En las demás ciudades, los hombres como nosotros [los filósofos] no se abstienen sin razón, de participar en las cargas públicas, porque se han formado ellos mismo, a pesar de los gobiernos [...]. Pero nosotros os hemos formados jefes y reyes [...] en interés de vosotros mismos y de los demás ciudadanos [...] os hemos vuelto capaces de unir la filosofía a la política" (Ibíd.: 346). 
está funcionado de manera recta y justa, del mismo modo que asegurar su vitalidad es de cierto modo invertir en buenos gobernantes futuros.

La filosofía en este contexto platónico se transforma así en un ejemplo, en una constatación, de que el estado está funcionando de manera exitosa, en cuanto es capaz de permitir y proteger su ejercicio. Platón fue ciertamente mucho más allá, ubicando al filósofo como el gobernador de dicho estado, haciendo de esta protección y de la actividad filosófica una manera de asegurar la formación constante de buenos gobernantes. Así, como es posible apreciar, se reemplaza la valoración de los "hechos y palabras", por la centralidad fundante que representa, para el estado, el ejercicio de la "vita contemplativa".

Así, el disponer platónico de la otrora vida política en razón de la actividad filosófica, ejemplifica paradigmáticamente la transgresión de la política. Transgresión que tiene como base la experiencia a-política, o quizás política en otros términos, que representa la reducción de "los muchos" en "los pocos" que se efectúa en la Academia, en la re-formulación de la "libertad de movimiento" en la "libertad de cátedra" 24 . Libertad ésta ya no de actuar, pero sí de hablar y aparecer ante los demás. Grupo que ya no está conformado por el número indefinido que conforma la pluralidad de "los muchos" en la escena pública, sino se reduce a aquellos que son admitidos dentro de los muros de la Academia.

Proceso de selección y reducción de los "muchos" en los "pocos" que, al menos para Arendt, no puede ser efectuado sin desplazar y modificar de manera profunda el sentido de la política y su relación con la libertad. Arendt especifica el sentido de este desplazamiento, cuando nos señala que:

Es evidente que siempre que los pocos se han separado de los muchos -sea en la forma de una indiferencia académica, sea en la forma de un dominio oligárquico- ha dependido de los muchos en todas las cuestiones del con-vivir en las que realmente hay que actuar (Ibíd.: 83).

24 "[L]a fundación de la academia, que, si bien se enfrentó a la polis al auto-delimitarse frente al territorio propiamente político, también siguió precisamente el sentido de este espacio [...] en la medida en que el hablar los unos con los otros fue su contenido auténtico. Con ello surgió junto al territorio libre de lo político un espacio nuevo de la libertad [...] que ha llegado a nuestros días como la libertad de las universidades y la libertad académica de cátedra" (Arendt, 2009: 81). 
Podemos comprender, a raíz de este fragmento, que lo paradigmático del caso platónico es que de cierta forma aúna ambos motivos tras la separación de "los muchos", al tensionar el abandono de la polis por parte de los "amantes de la sabiduría" hacia la pretensión, por cierto oligárquica, de ubicar precisamente al "filósofo-rey" en la posición del gobernante. Más allá de este caso aparentemente excepcional, lo que al menos en este lugar Arendt rescata, es que tras este gesto separatista existe, ya sea bajo la forma de una oligarquía o incluso de la propia Academia, una relación de dependencia con "los muchos" que se inscribe dentro del registro del "con-vivir" y de la acción. En el caso de la oligarquía, "los pocos" definen su relación con "los muchos" a partir de un régimen de mando y obediencia, donde son los gobernantes los que inician un proceso y son los gobernados los que deben llevarlo a cabo ${ }^{25}$.

Por su parte, la Academia modula su relación con "los muchos" a partir de su necesidad de protección y mantenimiento, de resguardo para el ejercicio de una actividad que, bajo la forma del pensamiento, no produce beneficio material alguno. Es por este motivo que Arendt comprende la forma de esa relación a partir de la "benevolencia del cuerpo político" hacia su institución, vínculo que parece no haber sufrido mayor diferencia, al menos en este punto, hasta nuestros días. Benevolencia en tanto son "los muchos" los que permiten mantener la necesidad de sobrevivencia y el peso de la labor fuera de las preocupaciones de la Academia, permitiendo acuñar ahí un espacio de aparición y de "cierta" libertad de discurso. "Cierta", considerando la jerarquía vertical que un espacio de esa índole supone.

Lo significativo de esta salida de la polis, de la inserción de estas divisiones en su unidad primigenia, de esta parcelación de su pluralidad, es el nuevo sentido que adopta la libertad y su relación con la escena pública. Si la oligarquía introduce una división entre aquellos que pueden comenzar un nuevo proceso y aquellos que deben llevarlo a cabo, la Academia desplaza el sitial de la libertad desde la escena pública, desde su original espacio de aparición, hacia la escena privativa o selectiva de su institución. Mediante este proceso, la libertad, comprendida como la posibilidad de "compartir palabras y actos", no es sólo puesta en duda por la razón filosófica, sino que a su vez es dispuesta al servicio y protección de la "libertad de cátedra",

25 Relación que Arendt retrotrae, en palabras de Abensour, a la "[...] disociación del binomio árkehin/práttein (comenzar y actuar), que define el ejercicio de la política en la ciudad hasta el punto de venir a reemplazar a otra distinción, la que existe entre mandar y ejecutar" (Abensour, 2009c: 241). 
síntesis del libre ejercicio del pensamiento ${ }^{26}$. En este sentido, la política se vuelve así una preocupación para la Academia, en tanto es necesario asegurar la "benevolencia del cuerpo político" para posibilitar la existencia de su institución y es ese el prejuicio o sesgo que la filosofía política, en tanto «empresa académica», ha reproducido hasta nuestros días.

Así, la influencia que el pensamiento, este "modo existencial", ejerce sobre la valoración de la polis, ya sea en razón de las condiciones de posibilidad de su ejercicio o de la peligrosidad que guarda la falta de institución para los libre pensadores, como lo constata el caso de Sócrates, pareciera inscribir un defecto estructural a la pretensión filosófica por abordar la política. Tendencia, pues, a considerar la dimensión que el "vivir juntos" modula, en razón de una actividad que por definición se sustrae de esa unidad de "los muchos" hacia la comodidad y tranquilidad de "unos pocos", incluso hacia la soledad personal. Así, si seguimos a Arendt en esto y asumimos este defecto como constitutivo de la institución filosófico política, ¿existe alguna posibilidad aún de pensar la política como dotada de una dignidad y sentido propio desde la filosofía? ¿Es posible concebir una filosofía política capaz de eludir este prejuicio o sesgo estructural a su fundación? ¿Concebir así una "verdadera filosofía política", una filosofía política que, "liberada de sus defectos" (Abensour, 2009c: 256), de sus "vicios" (Ibíd) y sus sesgos, pudiera permitirnos el acceso a esta dimensión de lo político que la alemana nos enseña?

Preguntas éstas que la posición díscola de Hannah Arendt parece responder de manera negativa, siendo necesario, para ella, abandonar las filas de la filosofía política para descubrir el velo que la filosofía tiende sobre "los asuntos humanos". Posición que, si bien presenta una suerte de respuesta hacia estas interrogantes, no concuerda o satisface en plenitud a las pretensiones de la reflexión que Abensour emprende con la alemana. Ya que, ¿no está Abensour leyendo en Arendt una posibilidad, un pasaje, para asentar o entrever una nueva filosofía política? ¿No se aboca nuestro autor a la búsqueda de una oportunidad crítica en la obra de Arendt, de abandonar la Academia, de sortear el gesto que su empresa describe, para poder acceder a una dimensión política no velada? Y por otra parte, ¿es suficiente respuesta la negación pública de Arendt a la militancia o pertenencia al grupo de los filósofos, para escapar o sortear este sesgo institucional? Con el propósito de

26 Sería interesante analizar qué tanto de este concepto de Academia permanece con nosotros hoy en día y qué alteraciones en él se producen una vez que esa reducción de "los pocos" adopta no tan sólo el filtro de la supuesta inscripción platónica "aquí no entra nadie que no sepa geometría”, sino el aun más exhaustivo y excluyente filtro monetario. 
entregar algún sentido a estas interrogantes, debemos explicitar brevemente los matices que la lectura de Abensour despliega sobre la reflexión arendtiana.

\section{Desmontaje y resistencia, o el contra de Arendt}

En vista a atender estas inquietudes debemos, como primera medida, dejar en claro que nuestro autor se esfuerza por destacar, problematizar y resguardar la distancia que Arendt toma de la filosofía política. Resguardo que va más allá de una aclaración preliminar o un factor accidental o secundario, señalándonos que:

[L]a lectura de Arendt será distinta -si tomamos, o no tomamos, en cuenta- esta lucha contra la tradición. Si la minimizamos, o no la tomamos en serio, [...]; si trabajamos en hacer de H. Arendt una de las más grandes filósofas políticas de nuestro tiempo, desembocaremos rápidamente en una $\mathrm{H}$. Arendt canónica, momificada, petrificada, que pronto funcionará como una autoridad que servirá para legitimar los conservadurismos existentes [...] (Ibíd.: 262, 263).

En efecto, los riesgos de obviar o soslayar la posición díscola de la alemana con respecto a la filosofía política no son menores ni deben ser aminorados. En cierto sentido, esta advertencia de Abensour nos indica el profundo peligro que habita en el "gesto restaurador", panorama donde cualquier reflexión, por muy disidente que ésta se muestre, puede ser reducida o reconducida a determinada forma de legitimación de los "conservadurismos existentes" ${ }^{27}$. La reducción se hace posible precisamente cuando el "contra" es eliminado de nuestro análisis, haciendo de Arendt una especie de filósofa política.

Así, con el objetivo de preservar este "contra", rescatando la capacidad que posee la obra arendtiana de sortear y resistir este impulso restaurador por asimilar su figura a sus filas, Abensour concibe su reflexión no sólo como una "figura de resistencia", sino que ya al final del ensayo que aquí

27 Podemos simplemente mencionar una de estas figuras que leen en Arendt ya no la pensadora rebelde o disidente como Abensour nos enseńa, sino como un ejemplo del "sofisma" en la política, comprendiendo tras la defensa y revalidación de la opinión que la alemana efectúa, una defensa de la "democracia parlamentaria". Nos referimos, por cierto, a Badiou, quien señala:"Sabemos qué es esta idea [de que la política reside por completo en la opinión]: sofista. Y es, ya [...] lo que me parece ser la "política" en el sentido de Arendt y Myriam Revault d'Allonnes: sofista en el sentido moderno de la palabra, es decir, consagrada a la promoción de una política muy particular: la política parlamentaria" (Badiou, 2014). 
adoptamos como guía, admite la existencia en Arendt de la expresión de una "idea libertaria de la política" (Abensour, 2009c: 263). Atributo que resulta bastante difícil de definir y del que Abensour no entrega mayores pistas, pero que parece al menos indicar la capacidad que posee la obra de Arendt de tender un nexo entre su lectura de lo político y su concepción de la libertad. Posibilidad que la reflexión de la alemana no clausura dentro de su lectura de la antigua Grecia, de la polis o de ese episodio fundante, sino que adopta como una suerte de prisma, comprendiendo determinados y específicos acontecimientos de la historia occidental ${ }^{28}$ como muestras de la expresión de la libertad, y con ello de la pervivencia del tesoro político que esta concepción de la política es capaz aún de enseñarnos.

Experiencia política que permanece, que retorna nos diría Abensour, cada vez que esta "libertad de movimiento", tal como Arendt la concibe en tanto libertad de discurso y de acto, tiene lugar. En este sentido, podemos concebir esta idea libertaria como una clave de lectura, profundamente situada en su tiempo, tiempo que en cierta medida también es el nuestro, ofreciéndonos una forma de comprender una idea de la política en conjunción y sincronía con determinada experiencia de la libertad. Clave "libertaria" que parece aunar la originalidad de su idea de política con el ejercicio crítico que su gesto díscolo describe, haciendo de su salida de la filosofía política, de su posición de "exterioridad" (Abensour, 2009c: 262), una suerte de operación necesaria para contemplar lo político con los ojos puestos ya no en su necesidad, sino en la libertad. Expliquemos este paso con mayor detención.

Como ya mencionamos al comienzo de esta investigación, la lectura de Abensour comienza por constatar la existencia, en la reflexión arendtiana, de determinada forma de "resistencia" hacia la filosofía política. "Resistencia" que aquí hemos tratado ya no como una indiferencia, sino más bien como una operación compleja, que bajo la imagen del "desmontaje" se arroja a concebir los conceptos y nociones tradicionales de la política bajo el contraste y la luz que entrega la experiencia fundacional que les dio vida. Nos concentramos así en el concepto mismo de política, intentando concebir su sentido como el resultado de su aproximación o distancia con determinada idea de libertad. Dicho de otro modo, el sentido de la política, de su concepción, cambia de manera radical si entendemos su relación con

28 Acontecimientos que van más allá de la experiencia griega y que Arendt identifica, como otro de sus grandes ejemplos, con la Revolución Francesa, pero especialmente la Revolución Americana. Para un trato más extenso, véase Arendt, 2008. 
la libertad bajo la forma de la identidad o de la dependencia.

Libertad que examinamos dentro de las condiciones en las que Arendt la concibe, tomando como punto de partida la definición que nos entrega de la "libertad de movimiento" y arribando por medio de ésta al universo que representa la polis, y sus actividades constituyentes: acción y discurso. En ese análisis, la "libertad de movimiento" -comprendida como la libertad de actuar e iniciar nuevos procesos y de hacerlo en un espacio público donde dicho actos se comparten por medio de palabras o discursos-, se muestra no tan sólo como un derecho a ejercer una capacidad humana, sino que dichas actividades fundan y dan sentido al conjunto humano que las comparte. En otras palabras, acción y discurso, en tanto actualización de las condiciones de "natalidad" y "pluralidad", modulan una formulación del "vivir juntos", conformando un lugar en el cual la convivencia humana adquiere sentido, en tanto espacio donde la libertad tiene lugar. Acción y discurso fundan un "espacio de aparición", fundan una escena pública y fundan, de esta manera, la polis. Su realización es idéntica a la realización de la libertad porque la misma definición (griega) del ser libres coincide con la posibilidad para actuar y hablar en el espacio que estas actividades inauguran.

Constatado y formulado ya el nexo específico entre acción, discurso y libertad, la operación de "desmontaje" es puesta en marcha, concentrando su atención en la alteración que sufre este nexo en su resignificación filosófica. Proceso que contemplamos haciendo nuestra la invitación que Abensour nos hace: abandonar las filas de la "empresa académica" y el "gesto restaurador" que esta describe, intentando concebir en Arendt un ejemplo de esta salida. Búsqueda que encuentra asilo bajo el examen crítico que la alemana efectúa de la Academia platónica, en consideración de la reducción que ésta efectúa de "los muchos" en "los pocos" y de la transformación que el concepto de libertad experimenta a partir de este desplazamiento. Transformación que adquiere su modulación bajo la imagen del retiro de los filósofos de la polis, de su aparente renuncia a compartir hechos o actos en su acepción arendtiana, pero que adquiere su sentido pleno cuando la política se transforma en una preocupación para la filosofía. Paso que está motivado, por cierto, por el episodio socrático, pero que según la Arendt que aquí hemos leído, responde a una dependencia estructural que "los pocos" mantienen con "los muchos", cada vez que esa división es realizada. Dependencia que supone tanto la protección de la libertad para hablar, enseñar y compartir ideas -acciones que determinan lo que Arendt entiende por "libertad de cátedra"-, como también el aseguramiento de las condiciones materiales para que el ejercicio del pensamiento tenga lugar. 
"Desmontaje" que se muestra así como capaz de revelar precisamente el arraigo político del acercamiento filosófico a la polis. El cual no estaría, como nos enseña Platón, motivado por la "compasión" o la "responsabilidad" con los demás, sino que más bien pretende reorganizar ese conjunto social en razón del ejercicio filosófico, de la seguridad y protección de sus participantes.

En este sentido, podemos comprender la reticencia de Arendt a ser considerada "filósofa" no tan sólo como un intento simple de salir de la tradición y escapar a los vicios que la constituyen, sino que lo que este gesto demuestra es la negativa de la alemana a ocupar la posición que conlleva este título. Posición que, bajo su análisis de la tradición filosófica, está determinada por la retirada y separación que el "filósofo" lleva a cabo de la polis. Distancia que si seguimos a Arendt es entendida como estructural de nuestra tradición de pensamiento, la que supone ya una distancia aparentemente insoslayable entre el filósofo y lo político, entre la "empresa académica" donde esta posición tiene lugar y los asuntos y problemas que el retorno de lo político nos presenta.

De este modo, podemos entender su rechazo a la filosofía política como una manera de tomar lugar, pero ya no a partir de un círculo o gremio determinado -en ese sentido, declarar su actividad como "teoría política" sería una opción estratégica-, sino para tomar o, más bien, recuperar el lugar de todo ciudadano, de cualquier persona ${ }^{29}$. Su posición díscola se entiende así como un rechazo a la división que, en este caso, se efectúa cuando el filósofo piensa la política desde una posición superior, "más alta", nos diría Platón.

Posición que no se conquista con el mero acto performativo de declararse fuera del "círculo de filósofos", o de la Academia, sino que es resultado de todo el proceso que aquí hemos estudiado, de una operación (en el caso de Arendt) sobre sus conceptos fundamentales, a la luz de la experiencia que les dio origen, para luego resignificar la relación que los constituye. Así, si los fundadores de la filosofía muestran su relación con la

29 Sobre este punto, resulta crucial el estudio que la alemana lleva a cabo sobre la obra de Kant y sus rendimientos en tanto filosofía política. En esta ocasión intentamos privilegiar la poca explorada reflexión sobre la Academia de Arendt, bajo las pistas e incentivos que nos otorga el mismo Abensour, pero esta imagen no estará completa hasta que recorra la línea de investigación que entrega Kant, la lectura arendtinana del Juicio y sus rendimientos políticos. Es sólo sobre esos lugares donde podemos realmente rastrear el sentido de esta nueva y verdadero thaumadzein filosófico-político. Sobre este punto, véase Abensour, 2006. 
polis como una preocupación secundaria, recreativa o incluso desinteresada, Hannah Arendt se esfuerza en desenmascarar las condiciones veladas y ocultas que esta posición esconde, haciendo de "los asuntos humanos" el objeto de su asombro ${ }^{30}$.

Operación que Abensour no sólo reconoce, sino que se esfuerza en destacar. Ya no para sumar a Arendt dentro de las filas de la filosofía política, sino para destacar el modo en que ella es capaz de enfrentar los prejuicios de la tradición filosófica, a la vez que logra generar un pasaje inédito hacia "la acción misma" y hacia la idea de política ahí contenida. De este modo, podemos optar por comprender por esta clave libertaria, a falta de una definición del propio Abensour, esta forma de resistencia que Arendt nos enseña que encuentra a partir de su ejercicio, de su "desmontaje", un pasaje inédito hacia la acción y sus acontecimientos, hacia las "cosas políticas" agregaría Abensour.

De este modo, ¿se encontrará en esta clave libertaria, en el modo como hace suya esta resistencia, la acepción arendtiana de un "contra"? El camino que ha tomando nuestra investigación nos obliga a admitir esta posibilidad momentáneamente como cierta.

En efecto, encontramos en Arendt un ejercicio que modula una formulación del "contra", que lo configura como una forma particular de resistencia, cuyo atributo específico consiste en una capacidad de no tan sólo evitar los gestos de esta "política de los filósofos", sino que es capaz de revelarlos y retrotraerlos a su experiencia significante. Experiencia que no sólo re-significa los conceptos que median nuestro acercamiento a la política, sino que lleva su sentido más allá de su límites conceptuales para concebirlos bajo la óptica de las actividades que los constituyen. En este sentido, esta re-significación se muestra como una sobre-significación, como el despliegue, sobre los conceptos de libertad, acción y política (ejemplos que aquí tratamos), de horizontes de sentido que rebasan su definición nominal e incluso el sentido común de nuestro tiempo, para llevarnos a esta suerte de contra-ejemplo que representa la polis.

30 El asombro es, según la lectura de Abensour, uno de los elementos de la filosofía que Arendt rescata y que componen su reflexión. Como si Arendt volviera el asombro por el ser de los filósofos hacia la pluralidad y la natalidad que habita en esta dimensión constitutiva de la condición humana. En su tono de pregunta característico, Abensour nos señala: “¿De la filosofía, en efecto, no guarda ella este momento esencial, a saber, el asombro? ¿Acaso no es este asombro el que es susceptible de revelar la condición ontológica de la pluralidad y de la natalidad? ¿No es el asombro mismo el único capaz de descubrir un nuevo comienzo? (Abensour, 2009c: 244). 
Sobre-significación de la tradición de pensamiento político que tiene como efecto arrojarnos hacia la política misma. Movimiento que Abensour recoge, al comprender la compleja posición "exterior" y díscola de Arendt como un ejemplo de la salida del "gesto restaurador", de esta re-vitalización continuista y acrítica de la filosofía política y de su institución. Interés de nuestro autor que de cierto modo responde a nuestra pregunta por sus intensiones con la alemana, al inscribir su reflexión dentro de las filas de aquellos que lograron sortear los influjos de la "empresa académica", para darnos un ejemplo de un "pensamiento de resistencia".

En ese sentido, ¿es Arendt un ejemplo de la filosofía política crítica que Abensour nos propone? Toda la evidencia que hasta el momento hemos recaudado sobre su reflexión parece apuntar a esa dirección. Sin embargo, da la impresión que los peligros de asumir esta afirmación como cierta son mucho más grandes que sus rendimientos, ofreciendo la posibilidad de obviar el punto capital del carácter libertario del pensamiento arendtiano, que, tal como aquí lo hemos interpretado, consiste precisamente en su resistencia a formar parte de toda filosofía política ${ }^{31}$.

Ahora bien, nuestro autor no detiene ahí su análisis, agregando un último elemento a nuestro paso por Arendt. Ingrediente que representaría la contrapartida arendtiana al acercamiento filosófico de la política y al que Abensour denomina como "concepción heroica de la política". Lectura en la que por cierto Abensour no está sólo, pero que más allá de la discusión de especialista sobre Arendt, agrega al menos un último factor a destacar en nuestra investigación. Intentando concebir una réplica de la alemana a "los puntos ciegos de la filosofía clásica" (Abensour, 2009: 259), nuestro autor nos señala lo siguiente:

Si la filosofía política, o la política de los filósofos, se caracteriza por el miedo a la acción, miedo a la acción de los ciudadanos susceptible de venir a turbar la serenidad de la vida filosófica, a la inversa, una concepción heroica de la política privilegia la acción hasta asegurar su preeminencia sobre toda teorización posible (Ibíd).

31 En efecto, nuestro autor nos señala: "UUna verdadera filosofía política», ¿este programa no expresa, tal vez sin pretenderlo, los límites de la crítica de H. Arendt? ¿Esta expresión no deja entender que, más allá de la filosofía política y de sus «vicios», posible acceder a otra filosofía política que, liberada de sus defectos, permitiera esperara una filosofía política en su verdad de la filosofía política? [...] ¿ O sólo se trata, so pretexto de esta exigencia, de reproducir y reforzar una ilusión consustancial al proyecto mismo de filosofía política? [...] No cabría alimentar el sueño de una filosofía política auténtica, pues lo que se rechaza sin condición, [...] es la idea misma de filosofía política [...]" (Abensour, 2009c: 255, 256). 
El "miedo" al que Abensour aquí se refiere adquiere su sentido en los efectos que la acción trae consigo, sobre todo cuando consideramos su ejercicio en la escena pública. En efecto, la acción es esta actividad que comienza nuevos procesos que, no sólo se muestran ante los demás, sino que también los invita a participar en ellos, multiplicando su fuerza bajo el esfuerzo de "los muchos" y que trae, como posible consecuencia, la alteración parcial o radical del orden establecido, precisamente porque es capaz de insertar o crear uno nuevo. Miedo que sería contrarrestado por esta concepción heroica, que se define como una reflexión que tiene como polo gravitacional la acción, en tanto su objetivo estriba en concebir la política en si misma.

En efecto, si la alemana acude a alguna definición de héroe, lo hace en la acepción homérica que ella misma nos entrega, en tanto "en su origen la palabra 'héroe' [...] no era más que un nombre que se daba a todo hombre libre que participaba en la empresa troyana y sobre el cual podía contarse una historia” (Arendt, 2000: 209). Definición literal, pero que en su uso figurativo Arendt utiliza como forma de destacar el carácter protagónico que posee el actor de una historia, producto de una acción memorable. En este sentido, el heroísmo no apunta a una cualidad sobrehumana de aquellos que se arrojan a la empresa de la acción, sino que designa más bien una cualidad inherente a su ejercicio, a saber, el necesario abandono de la esfera privada, de su seguridad y confort, para embarcarse en una actividad pública, con potencial contacto con los demás y con consecuencias por cierto inesperadas. Abandono templado por la valentía y el coraje.

Abensour atiende a esta relación inherente del heroísmo con la acción, pero que, bajo su interpretación del gesto arendtiano con la política, es ahora atribuida a la valentía ya no solamente que nos lleva a abandonar la privacidad del hogar para dirigirnos a una forma de actuar concertada, sino que también puede ser ahora un atributo de una forma de pensamiento o reflexión sobre la política. De modo que no sólo existiría un heroísmo propio del "actor político" (Abensour, 2009: 261), sino que también podríamos pensar en una forma de "”heroísmo de espíritu”" (Ibíd.: 262), cuestión que, a mi parecer, puede inducirnos a pesar que Abensour estaría de cierto modo borrando la distancia que Arendt se esfuerza en trazar y mantener entre los “dos modos existenciales" que política y espíritu representan.

No obstante, si suspendemos estas objeciones, al menos de esta investigación, podemos comprender cómo esta propuesta abensouriana se entronca con uno de los principios más claros y enérgicos de su pensamiento. 
Principio que nos invita a leer su proyecto filosófico político crítico no como una "empresa académica", sino como un "pensamiento de resistencia"32. Distinción ésta que no sólo adquiere sentido cuando es desplegada sobre nuestra lectura de Arendt. De hecho, recordemos que Arendt para nuestro autor es una "figura de resistencia", en tanto su pensamiento, ya no de modo accesorio o anecdótico, sino de manera integral y coherente, se estructura como un enfrentamiento abierto y sin tregua contra los vicios institucionales de nuestra tradición filosófico política. Lucha que se compone tanto de su posición "exterior" con respecto al "gremio filosófico", como de su operación de "desmontaje" sobre sus categorías.

Ahora bien, ¿qué sucede cuando proyectamos sobre esta forma de resistencia el factor heroico que Abensour nos entrega? ¿En qué condiciones queda entonces nuestra lectura de Arendt?

Si intentamos una articulación entre el principio abensouriano de la resistencia y la operación arendtiana con la tradición, podemos interpretar, en primer lugar, que la resistencia va mucho más allá de la mera oposición a aquello que se busca combatir. Supone, en cambio, un trabajo acucioso y riguroso, que alcanza su posición de "exterioridad", su "burla" (Abensour, 2009c: 262) nos dirá Abensour, al emprender un ejercicio de sobresignificación de determinada acepción de la tradición.

Bajo esta perspectiva, la alemana lograría despertar, a partir de su trabajo sobre estos momentos "impensados" de la tradición, "horizonte[s] insospechable $[\mathrm{s}]$ " 33 , inéditos. Sentidos de lo político que tensan las categorías y conceptos del pensamiento político más allá de su límite tradicional, destilando para ellos una significación novedosa. Así, el "contra" que Abensour elige como clave para leer a Arendt, su contra la filosofía politica, aparece como esta forma de resistencia que trabaja ya no a espaldas o por la tradición, sino a través de su continuidad y su historia. Imagen que nos muestra un trabajo sobre estos "puntos ciegos", sobre un sentido oculto que despierta a partir del ejercicio de resistencia que la operación de desmontaje nos propone, logrando así desplazar y "perturba[r] nuestros hábitos de pensamiento" (Abensouar, 2007: 192).

32 "[P]ensée de la résistance et non entreprise académique" (Abensour, 2009a: 62).

33 Sobre un contexto por completo diferente al de Arendt, pero describiendo una operación formalmente suficientemente similar para inferir la relación de esta sobre significación con el ejercicio de la alemana, Abensour nos señala que "el pensamiento asociado a horizontes innombrables, ligado a lo implícito, 'piensa en infinitamente más "cosas" que el objeto donde se fija" (Abensour, 2001: 53). 
Resistencia que no sólo nos arroja a la búsqueda de una experiencia política previa o primigenia, sino que tiene como consecuencia nuestra salida de una tradición que busca superponer sus conceptos y categorías sobre tal dimensión, a partir de la subsunción y subyugación de su condición "inclasificable, escandalos[a] y hetorodox[a]" (Abensour, 2009c: 262, 263). En este sentido, si la imagen clásica del filósofo político, platónico como es el caso que aquí adoptamos como paradigma, mira a los "asuntos humanos" desde lo alto, desde la posición de superioridad que le entrega su conocimiento de las ideas, Arendt lo hace desde el ágora, como una más entre "los muchos".

\section{Referencias bibliográficas}

Abensour Miguel (2001), La democracia contra el Estado. Traducción de Eduardo Rinesi. Ediciones Colihue S.R.L., Buenos Aires.

(2006), "Le retournement kantien: de la question de l'égalité à celle du sensus communis" en Hannah Arendt contre la philosophie politique? Sens \& Tonka, París.

(2007), “Hannah Arendt contra la filosofía política?” en Para una filosofía politica y critica. Anthropos Editorial, México.

(2007a), "El contra Hobbes de Pierre Clastres." en El espiritu de las leyes salvajes. Del Sol, Buenos Aires.

(2009), "Philosophie politique moderne et émancipation." en Pour une philosophie politique critique." Sens \& Tonka, París.

(2009a), "De quel retour s' agit-il?"en Pour une philosophie politique critique. Sens \& Tonka, París.

(2009b), “Pour une philosophie poitique critique?”,en Pour une philosophie politique critique. Sens \& Tonka, París.

(2009c), "Hannah Arendt contre la philosophie politique?”, en Pour une philosophie politique critique. Sens\&Tonka, París. 
Arendt Hannah (1977), The life of the mind. Harcourt, EE.UU.

(1990), "Philosophy and politics", Social Research, vol. 57,

$\mathrm{N}^{\circ} 1$.

(1996a), "La Tradición y la Época Moderna" en Entre el pasado y el Futuro ocho ejercicios sobre la reflexión politica. Ed. Península, Barcelona.

(1996b), "La Brecha Entre el Pasado y el Futuro" en Entre el pasado y el Futuro ocho ejercicios sobre la reflexión politica. Barcelona, Ed. Península, 1996.

(1996c) "El concepto de historia: antiguo y moderno" en Entre el pasado y el Futuro ocho ejercicios sobre la reflexión politica. Traducción Ana Poljak . Ed. Península, Barcelona.

(1996d) "Verdad y política." en Entre el pasado y el

Futuro ocho ejercicios sobre la reflexión politica. Traducción Ana Poljak. Ed. Península, Barcelona.

Press, Chicago.

(1998), The human condition. University of Chicago

(2000), La condición humana, traducción de Ramón Gil Novales. Ediciones Paidós, Buenos Aires.

(2002), La vida del espiritu, traducción de Carmen Corral. Ediciones Paidós, Buenos Aires.

(2005), "Comprensión y política. (Las dificultades de la comprensión)." en Ensayos de comprensión 1930 - 1954. Escritos no reunidos e inéditos de Hannah Arendt. Traducción de Agustín Serrano de Haro. Caparrós Editores, Madrid.

(2005a), “¿Qué queda? Queda la lengua materna.

Conversación con Günter Gaus" en Ensayos de comprensión 1930 - 1954. Escritos no reunidos e inéditos de Hannah Arendt. Traducción de Agustín Serrano de Haro. Caparrós Editores, Madrid.

(2008), Sobre la Revolución, traducción de Pedro Bravo.

Alianza Editorial, Buenos Aires. 
Carbó. Paidós, Barcelona.

, (2009) ¿Qué es la Política? Traducción de Rosa Sala

Badiou Alain (consulta: 30 de mayo 2014), "Contra la "filosofía política»", Traducción del francés por María Victoria Aranda. [en linea] <http:// es.scribd.com/doc/118641598/Badiou-Contra-la-filosofia-politica>

Mouffe Chantal (2007), "La política y lo político", en En torno a lo político. Traducción de Soledad Laclau. Fondo de Cultura Económica, Buenos Aires.

Platón (1988), Diálogos IV: La República. Introducción y traducción de Conrado Eggers Lan. Gredos, Madrid. 